\title{
At what age should we attempt to retrieve sperm from males with Klinefelter syndrome
}

\author{
Shanta Shepherd ${ }^{1}$, Robert Oates ${ }^{1,2}$ \\ ${ }^{1}$ Department of Urology, Boston University School of Medicine, Boston, MA, USA; ${ }^{2}$ Department of Urology, Boston Medical Center, Boston, \\ MA, USA \\ Contributions: (I) Conception and design: All authors; (II) Administrative support: None; (III) Provision of study materials or patients: None; (IV) \\ Collection and assembly of data: All authors; (V) Data analysis and interpretation: None; (VI) Manuscript writing: All authors; (VII) Final approval of \\ manuscript: All authors. \\ Correspondence to: Robert Oates, MD. Professor of Urology, Boston University School of Medicine, Boston, MA, USA; Vice-Chair, Department of \\ Urology, Boston Medical Center, 725 Albany Street, Shapiro 3B, Boston, MA, USA. Email: robert.oates@bmc.org.
}

\begin{abstract}
Klinefelter syndrome (KS) is a common disorder and almost every clinician in almost every sub-specialty of medicine will knowingly or unwittingly treat boys or men with a 47,XXY chromosomal constitution. Although there are numerous aspects of KS worthy of discussion, this contribution will focus specifically on the controversial, and as yet unresolved, issue of whether it is advantageous to harvest testis tissue from peri-pubertal or adolescent boys with KS in a heroic effort to preserve that child's chances of reproduction in his future adult life. What would be the rationale for that, how does the biology of spermatogenesis in the Klinefelter testis impact that decision, and what does the data show? The answer, assembled from a selection of seemingly disparate sources and directions, appears to be "No". We do not have to advocate for an aggressive approach, we do not have to preemptively preserve future fertility. We can justifiably wait until adulthood with equivalent chances of success.
\end{abstract}

Keywords: Azoospermia; Klinefelter syndrome (KS); testis sperm extraction (TESE)

Submitted Dec 19, 2019. Accepted for publication Apr 30, 2020.

doi: $10.21037 /$ tau-19-858

View this article at: http://dx.doi.org/10.21037/tau-19-858

Klinefelter syndrome (KS) is a complex disorder involving multiple organ systems and physiologic processes, as reviewed comprehensively by Kanakis and Nieschlag (1). In this contribution, we will focus on the debatable and provocative issue of when might be the optimal time to harvest testis tissue in hopes of discovering useable spermatozoa in the KS male. Is there a dominant, robust and defensible rationale that demands surgical testis tissue procurement [testis sperm extraction (TESE)] as soon as the diagnosis of $\mathrm{KS}$ is evident. Or does the data show, however, that the age at which TESE is performed should not be dictated by anything other than whether it is the right circumstance and moment in the KS male's life for such an intervention. That is, can we answer the vexing question: is there an ultimate fertility preservation advantage in pre- pubertal, peri-pubertal, adolescent or young KS men gained by early TESE, well before they are ready to conceive? To highlight the uncertainty that exists as regards these issues in those clinicians who would be seeing Klinefelter patients in their practice, Zganjar et al. designed a survey of current clinical practice questions and distributed it to members of The Society for the Study of Male Reproduction, the Pediatric Endocrine Society and the Endocrine Society (2). Although the response rate was low, they rightly concluded that, "Fertility preservation practices in adolescents with KS vary greatly within and between the specialties caring for these patients. These findings should guide future research and bighlight the importance of establishing clinical practice guidelines." Perhaps this review will move the field, even if only minimally, in that direction. 


\section{KS genotype and testicular phenotype}

KS occurs in approximately 1 in 600 males. It is not identified in all, however, as many men proceed along in life undiagnosed (3-5). The genotype is characteristically $47, \mathrm{XXY}$, the additional $\mathrm{X}$ chromosome arising from either a mitotic (early embryo) or maternal/paternal germ cell meiotic mishap. Diagnosis may be made as a fetus based on results of amniocentesis, chorionic villous sampling or maternal cell-free DNA testing (6). There are no tell-tale signs in infants, other than perhaps cryptorchidism, but occasionally a karyotype done for other reasons may reveal a 47,XXY aneuploidy (7). Learning difficulties in children may trigger a pediatrician's thought of KS as a possible etiology; while very small testis size, taller than expected height, or failure to virilize (an uncommon presentation) may also ignite a genetic diagnostic search (8). Finally, a 47,XXY chromosomal constitution may be discovered at the time of evaluation of male infertility and non-obstructive azoospermia or severe oligospermia (9). While there is no singular and consistent presentation, what is common to all $\mathrm{KS}$ males are very small testes with compromises in both functions of the testissperm and androgen production (10).

The size of the normal testis is $4-5 \mathrm{~cm}$ long and $2-3 \mathrm{~cm}$ wide and is a direct reflection of the collective mass of the thousand or so individual seminiferous tubules that loop out and back from the mediastinum testis. After the pubertal initiation of spermatogenesis, and when it has reached an adult pace, each tubule is filled to capacity with Sertoli cells, spermatogonia, primary and secondary spermatocytes, spermatids and spermatozoa. The interstitium (between the seminiferous tubules) contains, most importantly, testosterone-secreting Leydig cells. Precursors of spermatogonia migrate from the yolk sac to the gonadal ridges during early embryonic life to populate the newly-formed tubules (11). During this migration, they increase in number through mitotic expansion, a process which continues in earnest during the mini-puberty (the neonatal surge of pituitary gonadotropins beginning a few months after birth and continuing for several months thereafter), at which time some also differentiate to type A dark (Ad) spermatogonia. Hibernation sets in until the spring awakening of puberty when the full and unabated spermatogenic process commences (continuous mitotic and meiotic reduction divisions as well as morphological transformation of the haploid spermatid to the fully functional spermatozoan).

What is the natural history of the KS testis-why is it so exceedingly small (12)? It is believed that in the first year of life, there may be a gradual decline in the number of $47, \mathrm{XXY}$ spermatogonia but not nearly enough to explain fully the diminutive adult KS testis volume (5cc or so). Johannsen et al. demonstrated that the mini-puberty surge in gonadotropins, and the consequent rise in testosterone, was normal in 13 infants with KS as compared to control male infants (13). It is during the pubertal years, however, when the events that will determine the ultimate size (and function) of the KS testis begin to play out. The vast majority of $47, \mathrm{XXY}$ spermatogonia which populate the vast majority of the seminiferous tubules in each testis cannot complete the meiotic process and become apoptotic [normal $\mathrm{X}-\mathrm{Y}$ pairing is mechanistically reviewed in the mouse model by Kauppi et al. (14)]. Whether this is specific to the germ cells themselves (sex chromosomal trisomy), whether it is malfunction and failure of the Sertoli cells in their nutritive and supporting role (overexpression and resultant functional "toxicity" of X-linked, testis-expressed genes), or a combination of both is not fully understood (15). Tubules populated by these apoptotic germ cells wither and become largely fibrotic. A few remain with surviving 47,XXY spermatogonia but are devoid of complete spermatogenesis. On average, then, each tubule is either shriveled with few remaining germ and Sertoli cells or shrunken and devoid of all cells-each then possessing a girth only a fraction of normal. The totality of all of those minute tubules and/or remnants leads to an overall testis mass far from the typical, common length and width. So, where do the spermatozoa come from that are found upon TESE in approximately $50 \%$ of KS cases-an insightful question indeed.

\section{Spermatogenesis in the KS testis}

In a reverse twist of genetic fate, a spermatogonial germ cell, during a mitotic replication, might randomly and sporadically lose the supernumerary $\mathrm{X}$ chromosome and revert to a 46,XY spermatogonial germ cell with all of the proper machinery for normal mitosis, meiosis and spermiogenesis and with none of the Xtra baggage that was constraining to those processes. It is these euploid cells that are thought to be the progenitors of the haploid spermatozoa unearthed during TESE $(12,16,17)$. They initially and comfortably reside on the internal side of a lucky seminiferous tubule basement membrane as per usual, surrounded and enveloped by the nurturing Sertoli cells until they are roused from their pre-pubertal sleep and the spermatogenic sequence is initiated, the spawn of which are 
capable and competent haploid $23, \mathrm{X}$ or $23, \mathrm{Y}$ spermatozoa. This most likely of scenarios also explains why the reported babies born have been $46, \mathrm{XY}$ or $46, \mathrm{XX}$, confirming studies demonstrating that the preponderance of spermatozoa subjected to chromosomal analysis are indeed haploid. If $47, \mathrm{XXY}$ spermatogonia cannot complete the meiotic cascade [although some argue they might rarely be able to (18)] and, therefore, will not be the ancestors of any sperm found in the testis at any age (adolescent to adult), is there any reason to "cryopreserve" them by performing TESE at an early age, or at least well before the KS male is ready to have a child (19)? At the present moment, there is no in-vitro technology or culture system that can drive the expulsion of that extra $\mathrm{X}$ chromosome from all or even a fraction of the $47, \mathrm{XXY}$ spermatogonia and then, in addition, assist them in manufacturing functional, genetically safe haploid gametes. The answer to the query of whether we should be aggressive and surgically extract testis tissue from the pre-pubertal, peri-pubertal or adolescent Klinefelter testis in order to freeze all existing 47,XXY early germ cells in that morsel of tissue would appear to be a resounding "No". Indeed, in the review by Gies et al., they prudently offer this piece of advice, "banking testicular tissue from pre-pubertal KS boys should only be performed in a research framework" (20). But will this still be true tomorrow, or next year, or in a decade or two. Makar and Sasaki review the present science and state-of-the-art technology being used to study in vitro gametogenesis (21). Will their hopeful conclusion, "In vitro gametogenesis will constitute an emergent new field in human reproductive medicine in the near future" be applicable for the 47,XXY Klinefelter male-perhaps one day we will be able to generate haploid spermatozoa from 47,XXY cells.

\section{Adolescent or adult TESE: which is the best choice to maximize fertility?}

If we are not going to freeze pre-adult $47, \mathrm{XXY}$ spermatogonia for future use to insure fertility because of the limitations of our present technology, a new question arises. Should we be offering, even advising, that TESE with cryopreservation of any spermatozoa found be carried out in the adolescent or young adult male prior to the time at which the individual is trying to conceive with a partner. There are two intersecting lines of thought that generate this question. The first depends on Leydig cell testosterone production and what level is seen typically and what is the "lifespan" of that level. That is, do all KS young males require or benefit from testosterone supplementation and, whatever the level is at puberty, even if adequate, does it remain so? Will it drop precipitously through the teenage and early adult years such that all KS males will ultimately need testosterone supplementation or replacement and TESE might as well be carried out sooner than later since exogenous testosterone may/will decrease spermatogenesis-a result unwelcome if there is little sperm production capacity to begin with? The second driver behind early TESE is the thought that spermatozoal production is quantitatively maximal just after puberty and falls dramatically in the ensuing years. If this were true, then any delay in TESE would compromise future biologic paternity. That is, not intervening immediately and aggressively upon diagnosis would be an opportunity missed to preserve future chances of genetically-linked fatherhood. What a tragedy that would be-but does this supposed decline actually occur? Let's look at both of these arguments for early TESE and see if they are supported by the evidence.

\section{Question 1: Does testosterone production wane after puberty and would, therefore, replacement/ supplementation be necessary?}

This question is an important one because if testosterone levels did indeed decay steadily through the first few years following puberty to symptomatically low levels, an argument could be made to perform TESE before this actually happens. If it did, then is that a signal that spermatogenic capability is also deteriorating inexorably and simultaneously? The evidence suggests not. In 1985, Salbenblatt looked at the testosterone levels of 40 individuals with $\mathrm{KS}$ and noted that all entered puberty spontaneously between the ages of 11-14, all developed normal secondary sexual characteristics and that testosterone levels rose to the low-middle of the "normal range" and plateaued there into adulthood (22). Wikström et al. followed 14 Finnish 47,XXY boys and concluded that both onset and progression of puberty did not deviate from the pattern seen in $46, \mathrm{XY}$ control boys, that there was no difference in skeletal maturation between 47,XXY and 46,XY boys, testosterone levels of the KS boys fell within the normal range, and that SHBG and PSA levels were similar to the control boys. They state that, "we found no phenotypic evidence for androgen deficiency in boys with KS during early and mid-puberty" (23). Finally, they conclude as well, "no indisputable androgen deficiency appeared in KS boys, and thus they would require no androgen supplementation 
during early puberty". Aksglaede et al. reported on 166 boys, adolescents and adults with non-mosaic KS and found the same pattern: a rise at the onset of puberty to low-normal testosterone levels and a leveling off at those values such that there was no obvious and predictable diminution in testosterone output from the span of adolescence to adulthood, "the serum concentration is most often in the lower balf of the reference range of healthy males, and rarely below the reference range" $(24,25)$.

Clearly the value of testosterone is adequate in these boys/men, but are there other reasons that an individual may benefit from higher levels? The evidence is not conclusive but is ever evolving. One area that has received attention recently is bone health-is bone health optimized by supplementation or full replacement testosterone therapy in the adolescent and adult male with KS? If so, it may be a reason to begin treatment and, again, provide a push for TESE prior to the institution of that therapy. However, the data does not necessarily support this contention. Stagi et al., in their study involving $40 \mathrm{KS}$ children and adolescents, as well as 80 age-matched healthy subjects, noted that the KS patients had impaired bone mineral status, higher PTH levels, and reduced 25-OH-D and bone formation markers. What is of interest here is that these impairments were already discernable in pre-pubertal KS boys (26). In terms of bone health in the KS boy, it may not be all about testosterone. As Tahani et al. state after treating $15 \mathrm{KS}$ men with testosterone, "In untreated hypogonadal men with KS, lumbar and femoral BMD (bone mineral density) was reduced, and femoral bone quality was impaired... However, TRT (testosterone replacement therapy) failed to remedy these negative effects on bone" (27). Their conclusion was in agreement with that of Shanbhogue et al. who stated that while the indices of bone structure, bone strength, and bone biomarkers that they measured were compromised in the adult KS patients as compared to a control group, there was no significant difference in these indices in the $21 \mathrm{KS}$ patients on longterm testosterone therapy compared to the $11 \mathrm{KS}$ men not on long-term testosterone therapy (28). So at this time, it is not at all clear that the magic solution to any reduction in bone parameters that may be found in a KS man is testosterone replacement. It certainly is more convoluted than that simplistic linear relationship, perhaps involving other less well-known and studied proteins such as INSL3 and Sclerostin (29).

Are there other compelling reasons to prescribe testosterone replacement that would oblige a preemptive TESE? Increased height is found in many, but not all KS boys, and was thought to be a reflection of a hypogonadal state and, if indeed it were, would be an indicator of the need for testosterone therapy. However, increased stature in these boys is already recognized well before puberty begins when testosterone levels are minimal. This is most likely due to an increased dosage effect of the short stature homeobox-containing gene (SHOX) which is located on the pseudoautosomal region of both the $\mathrm{X}$ and $\mathrm{Y}$ chromosome (30). In the KS boy, 3 copies exist, not the normal 2 and increased linear growth may be the result. Therefore, when a KS boy is taller than his peers, it does not necessarily signal a hypogonadal state as may occur in a teenager with idiopathic hypogonadotropic hypogonadism.

What about the metabolic syndrome, in general, or specific conditions such as diabetes mellitus type 2 (T2DM) which is found in approximately $13 \%$ of Klinefelter men $(31,32)$. Is T2DM reversible or mitigated with testosterone therapy, even when started as an infant (33)? Probably not as O'Connor et al. point out, "observational data suggest that testosterone replacement is not associated with lower rates of diabetes or improved glycemic control" (34). Høst et al. are in agreement that while testosterone replacement may not improve glycemic control, it may help decrease total body and abdominal fat (indices of body composition) (35). There are also ongoing debates about whether an improvement in cognitive phenotype and brain development in $\mathrm{KS}$ infants/boys/teenagers/adults can be realized with timely testosterone treatment $(33,36)$. The data is unclear. So for now, there is little consensus in regards to absolute indications for tactical testosterone therapy and as Gravholt et al. conclude in their comprehensive review of the genetics, neuropsychology and endocrinology in KS, "Although hypogonadism is among the classic characteristics of $K S$, the effects of testosterone replacement therapy are not well studied, and many questions concerning timing, dose, and route of administration remain to be answered" (37). Finally, as this clinical conundrum continues to be clarified through prospective and focused research, we may be seeing an offroad that would be a compromise, in a way, between the polar ends of the spectrum: no testosterone therapy of any type at all before TESE versus unabashed testosterone treatment regardless of the timing of present or future TESE. This path may be illuminated by consideration of the type of testosterone therapy prescribed and the level of hypothalamic-pituitary suppression it causes. That is, as Garolla et al. document, the sperm retrieval rate (SRR) during TESE was similar (34\%) in those men on testosterone replacement therapy (TRT) and those men not 
on TRT, but only if there was minimal, if any, reduction in pituitary gonadotropin output, especially FSH (38). This is in line with data in Plotton et al. and Mehta et al. that also suggests that topical testosterone therapy may not be as suppressive as would be assumed $(39,40)$. Perhaps, there is some middle ground.

However, we must realize that in terms of the entire scope of phenotypic variation in the $47, \mathrm{XXY}$ KS individual seen as compared to the $46, \mathrm{XY}$ male, as discussed above, it is much more complex than just testosterone levels and androgen replacement. Quoting from Skakkebæk et al., "Characterization of the methylome as well as the transcriptome of both coding and non-coding genes identified a unique epigenetic and genetic landscape of both autosomal cbromosomes as well as the X chromosome in KS. A subset of genes show significant correlation between methylation values and expression values" (41). Panula et al. echoed and elaborated on those thoughts by looking at human induced pluripotent stem cells from two KS males and showed that the pattern of X chromosomal inactivation of the second $\mathrm{X}$ in the KS males was similar in many ways to the pattern of $\mathrm{X}$ chromosome inactivation of the second $\mathrm{X}$ in female pluripotent stem cells. In addition, they demonstrated that the differentially expressed genes between the 47,XXY KS men and two $46, \mathrm{XY}$ healthy males showed "enrichment in gene ontology terms associated with fertility, cardiovascular development, ossification, and brain development, all associated with KS genotype-related clinical features" (42). The genesis of many of the phenotypic variations known to occur in the 47, XXY male most probably has a rich and multifaceted genetic/ epigenetic basis, one not influenced nor ameliorated by testosterone or androgen replacement, respectively. In summary, there is little compelling and persuasive evidence to support a global approach to the KS adolescent in which all are automatically prescribed TRT. However, individualized treatment plans and strategies are always reasonable.

\section{Question 2: Is the early adolescent KS testicle more likely to have retrievable functional spermatozoa within it than the older adolescent KS testicle and is the older KS testicle more likely to have retrievable functional spermatozoa within it than the adult KS testicle?}

This question is the origin of the concept that the earlier a TESE is performed in young KS individuals, the better the outcome is vis-à-vis sperm recovery and future fertility.
As reviewed above, it is indeed true that there is massive germ cell loss at the start of the pubertal gonadotropin surge, but the cells lost are 47,XXY spermatogonia and their possible early spermatocyte derivatives. These cells are not meiotically competent and, therefore, loss of these cells is not equivalent to loss of fertility. The real question is whether spermatozoa are found more often in the adolescent (both early and late) KS testis upon TESE than in the older individual. Numerous studies now demonstrate that the rates in the older adolescent are equivalent to that in the adult and, furthermore, that rates of success in the adult are independent of age (see specific references below). Parenthetically, those rates of success also appear to be unrelated to the parent of origin (maternal or paternal) of the additional $\mathrm{X}$ chromosome (43).

Using studies that clearly define the exact age of the KS boys studied, we find that it is highly unlikely that actual testicular spermatozoa are found in any boy less than 15 years old. For example, in 2004 Wikström et al. reported on the histological analysis and search for spermatozoa in retrieved testis tissue in 14 non-mosaic KS boys (44). They found no spermatozoa in: 4 boys age 10, 5 boys age 11, 1 boy age 12, 2 boys age 13, and 2 boys age 14. Many years later, in 2012, Gies et al., using a single-site biopsy technique as Wikström did, found no sperm in a single 10 -year-old KS boy, no sperm in a pair of 12 -year-old boys, no sperm in 2 boys aged 13 and, no sperm in 2 slightly older boys aged 15 (45). In 2013, Rives et al. reported similar rates of non-success, detailing that no sperm was found on bilateral TESE in 2 boys who were 15 and only 1 of 3 boys aged 16 years (46). In 2015, Rohayem et al. reported their much larger series using a microsurgical TESE approach and documented finding spermatozoa in $1 / 10$ boys age $13-14,10 / 23$ age $15-16$, and $8 / 17$ age $17-19$ years (47). Also in 2015, Plotton et al. had both an adolescent group and an adult cohort for intra-study comparison (40). Her group performed TESE and compared the SRR between the "young" group (15-23 years old; SRR 57\%) and the "adult" group ( $>23$ years old; SRR 53\%). In their patients ages 15-16, 2/4 had sperm found; age 17, $3 / 5$ had sperm found; age 18, $3 / 6$ had sperm found; age 19, 4/6 had sperm found. Their adult rate was essentially equivalent to the rate of these older adolescents (see below as well). The following year, Nahata et al. described their results in a similar study to that of Plotton $e$ al. where they were able to compare SRRs in their own patients broken down by age, their youngest 15 years old (48). No sperm were found in a single 15 years old, $2 / 4$ in 16 years old, 1 in a single 17 years 


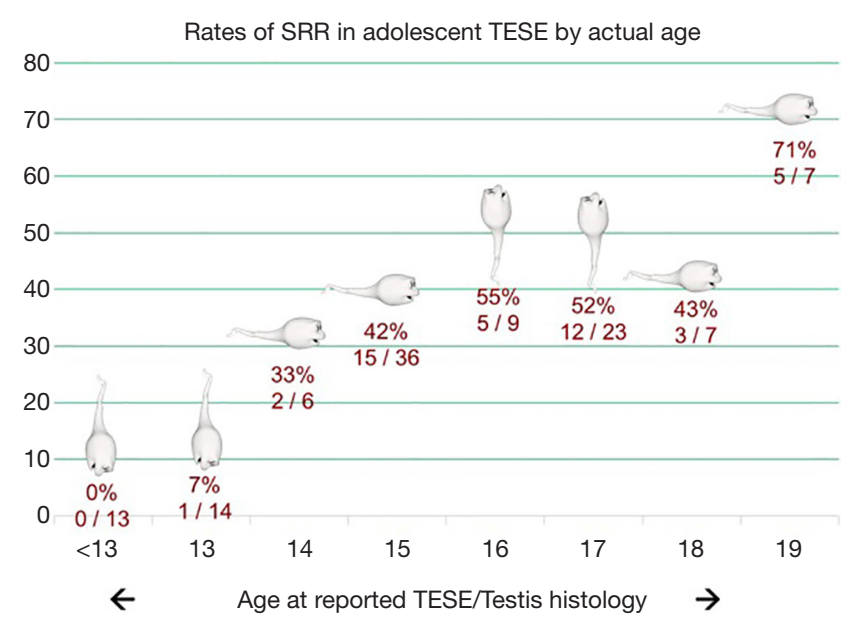

Figure 1 Graphical plot of the results of TESE or testis histology in assessing sperm presence in adolescents with KS less than age 19. Data are the combined numbers of published studies stratified by the actual age reported. The numerator is the number in that group with a positive result, the denominator is the total number of boys in that age grouping $(39,40,44-48,50)$.

old, no sperm in a single 18 years old, sperm present in a single 19 years old, no sperm in a 20 years old and sperm presence in a 23-year-old. Finally, Mehta et al., in 2013 and also using microTESE, found slightly better rates of $2 / 4$ 14 years old, 2/3 15 years old, and 2/2 16 years old (49). Of course, the original publication of Damani et al. was a case report of a single adolescent, age 15 , who had sperm present on microTESE (50). It is important to actually look at the very specific ages and success rates and not just ranges of ages in these publications. As Figure 1 clearly demonstrates, when the above studies are added together and plotted out graphically (precise age on the $\mathrm{X}$ axis and percent TESE success (SRR) on the $\mathrm{Y}$ axis; when only ages such as 13-14 were provided, data was added to the earlier age), there are, in point of fact, very few individuals who end up comprising these statistics. As importantly, however, is the clear demarcation of what can be considered "early" versus "late" adolescence, in terms of the SRR in KS males. Before the age of 15 , there is little success in finding sperm on TESE, or evidence of complete spermatogenesis on biopsy, with only 1 boy out of 33 collectively having a positive result. Just in regards to this particular age range then, Franik et al. offer this cautionary advice based upon their review of this literature, "Despite the common advice for adolescents with KS to undergo TESE as early as possible as being reported in some literature, we suggest a more expectant approach as previously recommended. Based upon the studies described in this work, (pre) pubertal TESE cannot be recommended to date" (51). The age at which they chose to discourage TESE was younger than 16 years.

We can conclude then, especially when presented with the visual evidence of SRRs displayed in Figure 1, that TESE as a means to harvest and cryopreserve functional spermatozoa in order to provide "fertility preservation" for the KS adolescent less than 15 years of age is doomed to failure and not clinically worthwhile. It is interesting to ask why there is the sudden jump in the boys 15 and older: is this a reflection of a relatively (compared to $46, \mathrm{XY}$ males) delayed expression of full spermatogenesis in the individual seminiferous tubules so endowed, or a quirk in how the data was gathered (biopsy $v s$. TESE $v s$. microTESE) in this earlier age group. Figure 1 also presents the data on the KS adolescents who were 15 and older and the dramatic change is success is visibly obvious. However, the data set is still comprised of fairly small numbers but the pattern is clear with successful SRRs in $50-60 \%$ of boys aged $15-19$. It is fair to inquire, then, whether this success rate is higher than that found in adults and, if so, potentially drive an approach of TESE in the older adolescent to preserve future biologic paternity.

Figure 2, 3 and 4 overlay on the original adolescent graphs the ranges of success in adults reported by Corona et al. (meta-analysis), Aksglaede et al. (review of the literature), and Van Saen et al. (a report of their own adolescent and adult KS patients), respectively $(24,52,53)$. What can be seen is that the adult rates are the same as the older adolescent rates. The range of SRR success determined by Corona et al. was $39-48 \%$, for Aksglaede et al. it was $47-69 \%$ and for the Van Saen et al. cohort, it was $48 \%$. With these studies, we can indeed also conclude that the rates of SRR in the older adolescent are not better than in the adult and, therefore, TESE in the adolescent is not mandatory and will not be helpful in preserving fertility that otherwise would be lost forever. To quote the studies explicitly, when Plotton et al. compared their own adolescent group to their older adult group, they state, “...performing TESE at a younger age (15-23 years) in patients with non-mosaic 47,XXY Klinefelter did not increase SRR relative to adult patients (24-39 years)" (40). Nahata et al. similarly advised, "Our sperm retrieval rate of $50 \%$ was similar to results of these studies, also suggesting there is no clear benefit to performing TESE/unilateral micro-TESE in adolescence" (48). In their meta-analysis, Corona et al. and, using their own patients, Van Saen et al., found no evidence of an adult age-related decline in TESE success suggesting 


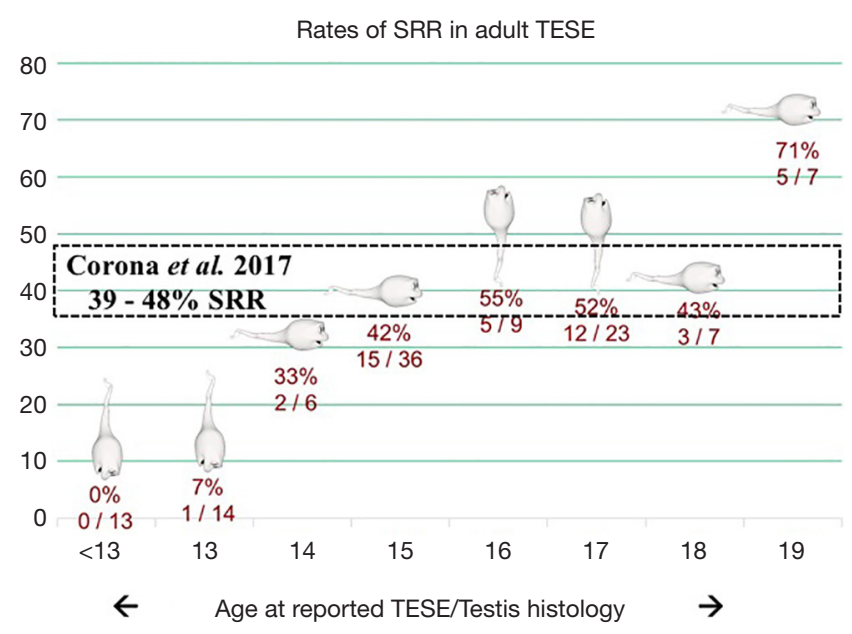

Figure 2 Range of KS adult sperm retrieval rates (39-48\%) determined by the Corona et al. meta-analysis superimposed on the adolescent rates of success as displayed in Figure 1 (52).

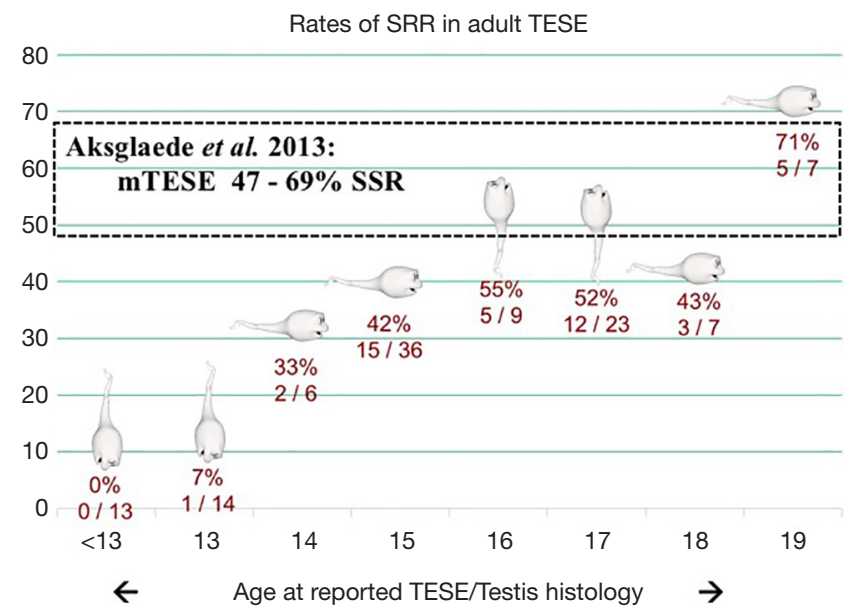

Figure 3 Range of KS adult sperm retrieval rates (47-69\%) determined by the Aksglaede et al. review superimposed on the adolescent rates of success as displayed in Figure 1 (24).

that there is no reason to push a young adult to have a TESE to "preserve" his future fertility potential $(52,53)$. In their study of $83 \mathrm{KS}$ men who underwent TESE at their institution, Vicdan et al. found no significant difference in the ages of those adult men with sperm present on TESE and those adult men in whom no sperm were found (54). A final summative quote from Garolla et al., who also noted no age-related difference in SRR reiterates this caution, "Because sperm recovery seems independent from age, the timing. of TESE and preservation can be left to patient's choice" (38).

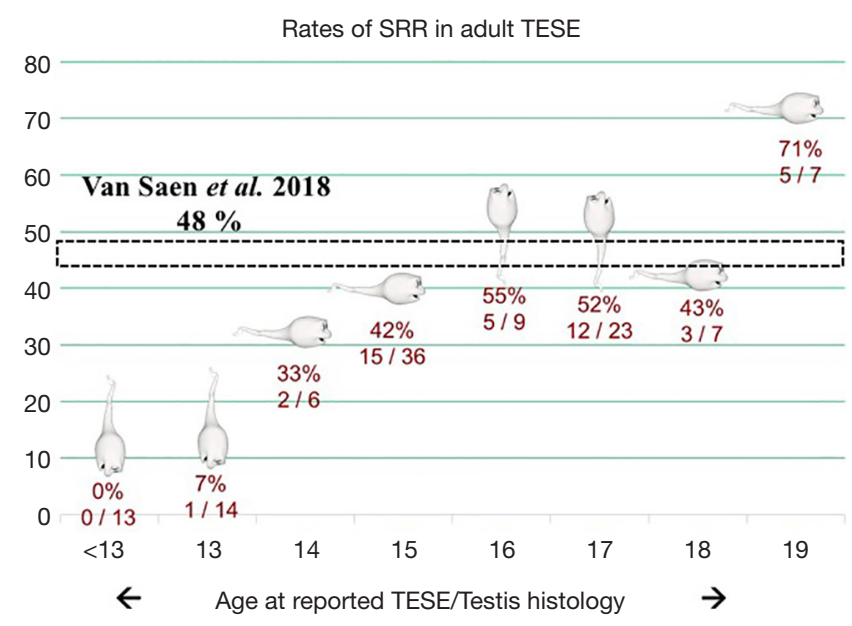

Figure $4 \mathrm{KS}$ adult sperm retrieval rate $(48 \%)$ determined by the Van Saen et al. study superimposed on the adolescent rates of success as displayed in Figure 1 (53).

In addition, it certainly appears that performing TESE as a microsurgical approach (microTESE), as compared to a random biopsy technique (conventional TESE or cTESE) is associated with a higher likelihood of sperm discovery $(24,55)$. In regards to the use of freshly retrieved sperm or the use of previously cryopreserved sperm from Klinefelter males, Vicdan et al. feel that, in their reproductive program, "The use of fresh or cryopreserved-thawed spermatozoa on ICSI cycle outcomes are equally successful in patients with KS" (54). However, Okuyama and colleagues reported that the use of freshly harvested sperm and freshly retrieved oocytes had a significantly better pregnancy and birth rate than the use of frozen-thawed sperm and fresh oocytes, $43.2 \%$ and $28.5 \%$ compared to $33.4 \%$ and $18.7 \%$ (56). At this time, the philosophy employed by the reproductive clinicians and embryologists involved in these cases, vis-àvis fresh vs. frozen sperm, is program specific and variable.

It is certainly reasonable to focus on the chances that sperm will be found during a TESE in the KS malewhatever age the TESE is carried out-as this at the very least provides the opportunity for pregnancy in the female partner when what is harvested is used as the sperm source for a cycle(s) of ICSI. That is, the rates of sperm retrieval are not equivalent to the live birth rate and couples undergoing TESE/ICSI should be aware. By the estimates of Vloeberghs et al., only $10.1 \%$ of couples in their cohort of 138 non-mosiac Klinefelter man and their partners succeeded in having an offspring via TESE in combination with ICSI (57). Of course, that will fluctuate up and down 
dependent upon many factors such as female age, experience with TESE, proficiency in working with testis sperm.

\section{Conclusions}

The anxiety surrounding the concept of proactive TESE in the adolescent (and even adult) 47,XXY Klinefelter male seems unwarranted for both clinicians, patients and their families. There is no compelling evidence that a 16-year-old KS patient will quickly and unavoidably lose some presumed high level of sperm production over the next several years such that if TESE is not strongly recommended, forever lost will be his chance of biological and genetic fatherhood. Indeed, the same holds true for the adult male with KS. As Oates has opined, the same individual human Klinefelter male who has sperm present in the testis at age 16 will be the same individual human Klinefelter male who will have sperm present at age 30 (19). Conversely, if no sperm are present at 16 , no sperm will be found at age 30 . Where is the rush? In addition, there seems to be little data suggestive of an absolute need for testosterone replacement in all KS boys that would complicate the decision of whether a TESE should be performed or not prior to the institution of that therapy. Of course, there will indeed be a small population of KS boys who are not virilizing at all (the extreme end of the endocrinological spectrum) and will benefit from TRT. However, there is an increased awareness of the phenotypic issues common to the $\mathrm{KS}$ male and newer research avenues are being explored and the results disseminated. For now, we should have a more relaxed position vis-à-vis the timing of TESE.

\section{Acknowledgments}

Funding: None.

\section{Footnote}

Provenance and Peer Review: This article was commissioned by the Guest Editors (Keith Jarvi and Jared Bieniek) for the series "Genetic Causes and Management of Male Infertility" published in Translational Andrology and Urology. The article was sent for external peer review organized by the Guest Editors and the editorial office.

Conflicts of Interest: Both authors have completed the ICMJE uniform disclosure form (available at http://dx.doi. org/10.21037/tau-19-858). The series "Genetic Causes and Management of Male Infertility" was commissioned by the editorial office without any funding or sponsorship. The authors have no other conflicts of interest to declare.

Ethical Statement: Both authors agree to be accountable for all aspects of the work in ensuring that questions that related to the accuracy or integrity of any part of the work are appropriately investigated and resolved.

Open Access Statement: This is an Open Access article distributed in accordance with the Creative Commons Attribution-NonCommercial-NoDerivs 4.0 International License (CC BY-NC-ND 4.0), which permits the noncommercial replication and distribution of the article with the strict proviso that no changes or edits are made and the original work is properly cited (including links to both the formal publication through the relevant DOI and the license). See: https://creativecommons.org/licenses/by-nc-nd/4.0/.

\section{References}

1. Kanakis GA, Nieschlag E. Klinefelter syndrome: more than hypogonadism. Metabolism 2018;86:135-44.

2. Zganjar A, Nangia A, Sokol R, et al. Fertility in Adolescents With Klinefelter Syndrome: A Survey of Current Clinical Practice. J Clin Endocrinol Metab 2020;105:dgz044.

3. Abramsky L, Chapple J. 47,XXY (Klinefelter syndrome) and 47,XYY: estimated rates of and indication for postnatal diagnosis with implications for prenatal counselling. Prenat Diagn 1997;17:363-8.

4. Bojesen A, Juul S, Gravholt CH. Prenatal and postnatal prevalence of Klinefelter syndrome: a national registry study. J Clin Endocrinol Metab 2003;88:622-6.

5. Shiraishi K, Matsuyama H. Klinefelter syndrome: From pediatrics to geriatrics. Reprod Med Biol 2018;18:140-50.

6. Samango-Sprouse C, Keen C, Sadeghin T, et al. The benefits and limitations of cell-free DNA screening for 47, XXY (Klinefelter syndrome). Prenat Diagn 2017;37:497-501.

7. Davis SM, Rogol AD, Ross JL. Testis Development and Fertility Potential in Boys with Klinefelter Syndrome. Endocrinol Metab Clin North Am 2015;44:843-65.

8. Davis S, Howell S, Wilson R, et al. Advances in the Interdisciplinary Care of Children with Klinefelter Syndrome. Adv Pediatr 2016;63:15-46.

9. Bearelly P, Oates R. Recent advances in managing and 
understanding Klinefelter syndrome. F1000Res 2019;8. doi: 10.12688/f1000research.16747.1.

10. Lanfranco F, Kamischke A, Zitzmann M, et al. Klinefelter's syndrome. Lancet 2004;364:273-83.

11. Hughes IA. Minireview: sex differentiation. Endocrinology 2001;142:3281-7.

12. Oates RD. The natural history of endocrine function and spermatogenesis in Klinefelter syndrome: what the data show. Fertil Steril 2012;98:266-73.

13. Johannsen TH, Main KM, Ljubicic ML, et al. Sex Differences in Reproductive Hormones During MiniPuberty in Infants With Normal and Disordered Sex Development. J Clin Endocrinol Metab 2018;103:3028-37.

14. Kauppi L, Jasin M, Keeney S. The tricky path to recombining $\mathrm{X}$ and $\mathrm{Y}$ chromosomes in meiosis. Ann N Y Acad Sci 2012;1267:18-23.

15. Winge SB, Dalgaard MD, Belling KG, et al. Transcriptome analysis of the adult human Klinefelter testis and cellularity-matched controls reveals disturbed differentiation of Sertoli- and Leydig cells. Cell Death Dis 2018;9:586.

16. Garcia-Quevedo L, Blanco J, Sarrate Z, et al. Hidden mosaicism in patients with Klinefelter's syndrome: implications for genetic reproductive counselling. Hum Reprod 2011;26:3486-93.

17. Sciurano RB, Luna Hisano CV, Rahn MI, et al. Focal spermatogenesis originates in euploid germ cells in classical Klinefelter patients. Hum Reprod 2009;24:2353-60.

18. Komsky-Elbaz A, Raziel A, Ben-Ami I, et al. Ploidy of spermatogenic cells of men with non-mosaic Klinefelter's syndrome as measured by a computerized cell scanning system. J Assist Reprod Genet 2015;32:1113-21.

19. Oates R. Adolescent Klinefelter syndrome: is there an advantage to testis tissue harvesting or not? F1000Res 2016;5. doi: 10.12688/f1000research.8395.1.

20. Gies I, Oates R, De Schepper J, et al. Testicular biopsy and cryopreservation for fertility preservation of prepubertal boys with Klinefelter syndrome: a pro/con debate. Fertil Steril 2016;105:249-55.

21. Makar K, Sasaki K. Roadmap of germline development and in vitro gametogenesis from pluripotent stem cells. Andrology 2020;8:842-51.

22. Salbenblatt JA, Bender BG, Puck MH, et al. Pituitarygonadal function in Klinefelter syndrome before and during puberty. Pediatr Res 1985;19:82-6.

23. Wikström AM, Dunkel L, Wickman S, et al. Are adolescent boys with Klinefelter syndrome androgen deficient? A longitudinal study of Finnish 47,XXY boys.
Pediatr Res 2006;59:854-9.

24. Aksglaede L, Juul A. Testicular function and fertility in men with Klinefelter syndrome: a review. Eur J Endocrinol 2013;168:R67-76.

25. Aksglaede L, Skakkebaek NE, Almstrup K, et al. Clinical and biological parameters in 166 boys, adolescents and adults with nonmosaic Klinefelter syndrome: a Copenhagen experience. Acta Paediatr 2011;100:793-806.

26. Stagi S, Di Tommaso M, Manoni C, et al. Bone Mineral Status in Children and Adolescents with Klinefelter Syndrome. Int J Endocrinol 2016;2016:3032759.

27. Tahani N, Nieddu L, Prossomariti G, et al. Long-term effect of testosterone replacement therapy on bone in hypogonadal men with Klinefelter Syndrome. Endocrine 2018;61:327-35.

28. Shanbhogue VV, Hansen S, Jorgensen NR, et al. Bone geometry, volumetric density, microarchitecture, and estimated bone strength assessed by HR-pQCT in Klinefelter syndrome. J Bone Miner Res 2014;29:2474-82.

29. Di Nisio A, De Toni L, Rocca MS, et al. Negative Association Between Sclerostin and INSL3 in Isolated Human Osteocytes and in Klinefelter Syndrome: New Hints for Testis-Bone Crosstalk. J Clin Endocrinol Metab 2018;103:2033-41.

30. Ottesen AM, Aksglaede L, Garn I, et al. Increased number of sex chromosomes affects height in a nonlinear fashion: a study of 305 patients with sex chromosome aneuploidy. Am J Med Genet A 2010;152A:1206-12.

31. Han SJ, Kim KS, Kim W, et al. Obesity and Hyperglycemia in Korean Men with Klinefelter Syndrome: The Korean Endocrine Society Registry. Endocrinol Metab (Seoul) 2016;31:598-603.

32. Salzano A, D'Assante R, Heaney LM, et al. Klinefelter syndrome, insulin resistance, metabolic syndrome, and diabetes: review of literature and clinical perspectives. Endocrine 2018;61:194-203.

33. Davis SM, Reynolds RM, Dabelea DM, et al. Testosterone Treatment in Infants With 47,XXY: Effects on Body Composition. J Endocr Soc 2019;3:2276-85.

34. O'Connor MJ, Snyder EA, Hayes FJ. Klinefelter Syndrome and Diabetes. Curr Diab Rep 2019;19:71.

35. Høst C, Bojesen A, Erlandsen M, et al. A placebocontrolled randomized study with testosterone in Klinefelter syndrome: beneficial effects on body composition. Endocr Connect 2019;8:1250-61.

36. Foland-Ross LC, Ross JL, Reiss AL. Androgen treatment effects on hippocampus structure in boys with Klinefelter syndrome. Psychoneuroendocrinology 2019;100:223-8. 
37. Gravholt CH, Chang S, Wallentin M, et al. Klinefelter Syndrome: Integrating Genetics, Neuropsychology, and Endocrinology. Endocr Rev 2018;39:389-423.

38. Garolla A, Selice R, Menegazzo M, et al. Novel insights on testicular volume and testosterone replacement therapy in Klinefelter patients undergoing testicular sperm extraction. A retrospective clinical study. Clin Endocrinol (Oxf) 2018;88:711-8.

39. Mehta A, Paduch DA. Klinefelter syndrome: an argument for early aggressive hormonal and fertility management. Fertil Steril 2012;98:274-83.

40. Plotton I, Giscard d'Estaing S, Cuzin B, et al. Preliminary results of a prospective study of testicular sperm extraction in young versus adult patients with nonmosaic 47,XXY Klinefelter syndrome. J Clin Endocrinol Metab 2015;100:961-7.

41. Skakkebæk A, Nielsen MM, Trolle C, et al. DNA hypermethylation and differential gene expression associated with Klinefelter syndrome. Sci Rep 2018;8:13740.

42. Panula S, Kurek M, Kumar P, et al. Human induced pluripotent stem cells from two azoospermic patients with Klinefelter syndrome show similar X chromosome inactivation behavior to female pluripotent stem cells. Hum Reprod 2019;34:2297-310.

43. Franik S, Smeets D, van de Zande G, et al. Klinefelter syndrome and fertility-Impact of X-chromosomal inheritance on spermatogenesis. Andrologia 2018;50:e13004.

44. Wikström AM, Raivio T, Hadziselimovic F, et al. Klinefelter syndrome in adolescence: onset of puberty is associated with accelerated germ cell depletion. J Clin Endocrinol Metab 2004;89:2263-70.

45. Gies I, De Schepper J, Van Saen D, et al. Failure of a combined clinical- and hormonal-based strategy to detect early spermatogenesis and retrieve spermatogonial stem cells in 47,XXY boys by single testicular biopsy. Hum Reprod 2012;27:998-1004.

46. Rives N, Milazzo JP, Perdrix A, et al. The feasibility of fertility preservation in adolescents with Klinefelter syndrome. Hum Reprod 2013;28:1468-79.

47. Rohayem J, Fricke R, Czeloth K, et al. Age and markers of Leydig cell function, but not of Sertoli cell function predict the success of sperm retrieval in adolescents and adults with Klinefelter's syndrome. Andrology 2015;3:868-75.

48. Nahata L, Yu RN, Paltiel HJ, et al. Sperm Retrieval in Adolescents and Young Adults with Klinefelter Syndrome: A Prospective, Pilot Study. J Pediatr 2016;170:260-5.e1-2.

49. Mehta A, Bolyakov A, Roosma J, et al. Successful testicular sperm retrieval in adolescents with Klinefelter syndrome treated with at least 1 year of topical testosterone and aromatase inhibitor. Fertil Steril 2013;100:970-4.

50. Damani MN, Mittal R, Oates RD. Testicular tissue extraction in a young male with 47,XXY Klinefelter's syndrome: potential strategy for preservation of fertility. Fertil Steril 2001;76:1054-6.

51. Franik S, Hoeijmakers Y, D'Hauwers K, et al. Klinefelter syndrome and fertility: sperm preservation should not be offered to children with Klinefelter syndrome. Hum Reprod 2016;31:1952-9.

52. Corona G, Pizzocaro A, Lanfranco F, et al. Sperm recovery and ICSI outcomes in Klinefelter syndrome: a systematic review and meta-analysis. Hum Reprod Update 2017;23:265-75.

53. Van Saen D, Vloeberghs V, Gies I, et al. When does germ cell loss and fibrosis occur in patients with Klinefelter syndrome? Hum Reprod 2018;33:1009-22.

54. Vicdan K, Akarsu C, Sozen E, et al. Outcome of intracytoplasmic sperm injection using fresh and cryopreserved-thawed testicular spermatozoa in 83 azoospermic men with Klinefelter syndrome. J Obstet Gynaecol Res 2016;42:1558-66.

55. Majzoub A, Arafa M, Al Said S, et al. Outcome of testicular sperm extraction in nonmosaic Klinefelter syndrome patients: what is the best approach? Andrologia 2016;48:171-6.

56. Okuyama N, Obata R, Oka N, et al. Long-term clinical outcomes of testicular sperm extraction and intracytoplasmic sperm injection for infertile men. Reprod Med Biol 2017;17:82-8.

57. Vloeberghs V, Verheyen G, Santos-Ribeiro S, et al. Is genetic fatherhood within reach for all azoospermic Klinefelter men? PLoS One 2018;13:e0200300.
Cite this article as: Shepherd S, Oates R. At what age should we attempt to retrieve sperm from males with Klinefelter syndrome. Transl Androl Urol 2021;10(3):1432-1441. doi: $10.21037 /$ tau-19-858 